\title{
Size of Tuber Propagule Influences Injury of 'Kennebec' Potato Plants by Constant Light
}

\author{
Kent E. Cushman ${ }^{1}$ and Theodore W. Tibbitts ${ }^{2}$ \\ Department of Horticulture, University of Wisconsin, Madison, WI 53706
}

Additional index words. Solanum tuberosum, Solanaceae, controlled environment, photoperiod, propagation, stress

\begin{abstract}
Chlorosis and necrotic spotting develop on the foliage of particular cultivars of potato (Solanum tuberosum $\mathbf{L}$.) when grown under constant light. 'Kennebec', a cultivar severely injured by constant light when propagated from tissue-cultured plantlets, also was injured when plants were propagated from small tuber pieces $(\approx 1 \mathrm{~g})$. However, plants did not develop injury when propagated from large tuber pieces $(\approx 100 \mathrm{~g})$. Plants from large tuber pieces grew more rapidly than plants from small tuber pieces. The role of plant vigor and carbohydrate translocation in controlling injury development is discussed.
\end{abstract}

The importance of environmental and genetic factors affecting the development of constant-light injury in two solanaceous species, potato and tomato (Lycopersicon esculentum Mill.), has been demonstrated. When grown under constant light, plants developed interveinal chlorosis and brown necrotic spotting on the adaxial surface of expanding leaves, with injury eventually stunting the growth of the plant (Arthur et al., 1930; Cao and Tibbitts, 1991; Hillman, 1956; Kristoffersen, 1963). Visible injury is preceded by a sudden loss of photosynthetic activity, starch content, and chloroplast membrane integrity in the affected tissue (Cushman et al., 1995).

This disorder has been termed "continuous irradiation injury" or "constant-light injury"; however, photoperiods that include up to $4 \mathrm{~h}$ of darkness within each 24-h period still result in injury (Hillman, 1956; Kristoffersen, 1963). In addition, unusually short or long light/dark cycles, such as a 6-h light/6-h dark or 24-h light/24-h dark photoperiod, induce this disorder in tomato (Highkin and Hanson, 1954; Hillman, 1956; Kristoffersen, 1963). Therefore, photoperiods that deviate greatly from 12-h light/12-h dark are injurious, and constant light is just one of many possible light regimes leading to injury.

Received for publication 17 June 1996. Accepted for publication 23 Aug. 1996. This research was supported by the College of Agricultural and Life Sciences, Univ. of Wisconsin, Madison; NASA's Graduate Student Researchers Program grant NGT50956; and NASA grant NCC-2-301. This paper represents a portion of the dissertation submitted by K.E.C. in partial fulfillment of requirements for a $\mathrm{PhD}$ in Horticulture at the Univ. of Wisconsin. The cost of publishing this paper was defrayed in part by the payment of page charges. Under postal regulations, this paper therefore must be hereby marked advertisement solely to indicate this fact.

${ }^{1}$ Former Graduate Research Assistant. Current address: North Mississippi Research and Extension Center; P.O. Box 456; Verona, MS 38879. To whom reprints requests should be addressed.

${ }^{2}$ Professor Emeritus.
Temperature also is an important factor. Diurnal temperature alternations of $8^{\circ} \mathrm{C}$ or more in magnitude prevent injury in plants of potato (Tibbitts et al., 1990) and tomato (Hillman, 1956; Kristoffersen, 1963) when grown under constant light. These studies have clearly shown that thermoperiods of alternating high and low temperatures can prevent injury and maintain normal growth.

Genotype strongly influences the occurrence of injury (Tibbitts et al., 1992). In that study, several cultivars of potato, such as 'Kennebec' and 'Superior', were severely injured by constant light, while others, such as 'Denali', 'Haig', and 'Russet Burbank', grew without injury under the same conditions. Some cultivars, such as 'Norchip', appeared to be partially tolerant of constant light, since leaves developing on the main stem of young plants became injured while leaves developing on lateral branches remained uninjured (Wheeler and Tibbitts, 1986).

In the present paper, we report that the size of the tuber propagule is yet another factor affecting the development of constant-light injury.

\section{Materials and Methods}

Plant material and growth conditions. Plants of 'Kennebec', a potato cultivar sensitive to constant light, were propagated from tissue-cultured plantlets or tuber pieces. Tissue-cultured plantlets were obtained from stem cuttings as described by Tibbitts et al. (1994), and tuber pieces were obtained from fieldgrown tubers that had been maintained in cold storage for $\approx 8$ months. Small tuber pieces were prepared by excising a single lateral bud ("eye"), along with a section of its subtending tuber tissue, with a 1.1-cm-diameter cork borer and then trimming the length of the plug to obtain a final mass of $1.0 \pm 0.1 \mathrm{~g}$. Only lateral buds from the medial region of the tuber were selected. Large tuber pieces were prepared by cutting tubers in half, removing the extreme apical or basal end, and trimming to a final mass of $110 \pm 40 \mathrm{~g}$. All lateral buds but one were removed from large tuber pieces by excising a small amount of tissue around and under each bud.

Plants were grown in $1.8-\mathrm{L}(15 \mathrm{~cm}$ in diameter) or $3.8-\mathrm{L}$ (18 cm in diameter) pots containing 1 moist peat : 1 vermiculite $(\mathrm{v} / \mathrm{v})$ medium (Redi-Earth, Horticultural Products, Milpitas, Calif.). A complete nutrient solution (Hammer et al., 1978), pH 5.0 to 5.5, was delivered in excess automatically to each pot four times daily. Walk-in growth chambers and growth rooms were used in these studies, and, unless otherwise noted, environmental conditions were $70 \%$ relative humidity, $18^{\circ} \mathrm{C}$ air, and $350 \pm 60 \mu \mathrm{mol} \cdot \mathrm{m}^{-2} \cdot \mathrm{s}^{-1}$ photosynthetic photon flux (PPF) provided by cool-white fluorescent lamps (Philips Lighting Co., Somerset, N.J.). Temperature, humidity, and light/dark periods were recorded at least four times each hour by an electronic monitoring system, and temperature and humidity were calibrated against weekly psychrometer measurements. PPF was measured with an LI-190 quantum sensor (LI-COR, Lincoln, Neb.) at the beginning of each experiment, and replications in each experiment were arranged in a randomized complete-block design according to PPF gradients in the chamber.

Tissue-cultured plantlets vs. small tuber pieces. In one study, growth of plants propagated from tissue-cultured plantlets was compared to that of plants propagated from small tuber pieces. Small tuber pieces were prepared, immediately planted into a tray of moist medium, and maintained at $\approx 21{ }^{\circ} \mathrm{C}$ on a laboratory bench under fluorescent lighting of $\approx 50$ $\mu \mathrm{mol} \cdot \mathrm{m}^{-2} \cdot \mathrm{s}^{-1} \mathrm{PPF}$. After 12 days, plantlets were selected that were of similar size to tissuecultured plantlets grown in a tissue propagation room for 21 days. Four plantlets of each type were transplanted into separate $1.8-\mathrm{L}$ pots and placed in a growth chamber under a 12-h light/12-h dark photoperiod. Plantlets were covered with plastic cups for 3 days to aid establishment and prevent desiccation. Seven days after transplant, the lighting was changed to constant light, and development of injury (necrotic spotting) was recorded daily.

Small vs. large tuber pieces. Two experiments were conducted to compare the growth of plants propagated from small vs. large tuber pieces. Tubers were selected for both experiments from the same supply of stored tuber material as that of the previous experiment. Tuber pieces of both sizes were prepared and immediately planted into 3.8-L pots, one piece per pot, with the lateral bud oriented upward and situated 1 to $2 \mathrm{~cm}$ below the surface of the medium. Six tuber pieces of each size were used in each experiment. From the time of planting, plants in Expt. 1 were grown under constant light and in Expt. 2 under a 16-h light/ 8-h dark photoperiod. Both experiments were conducted in the same growth chamber, with the start of Expt. 2 immediately following the end of Expt. 1. Commonly, only a single shoot emerged from small tuber pieces and several shoots from large pieces. When several shoots emerged, all but the most vigorous shoot were removed by severing the stems below the surface of the medium. The number of plants 
exhibiting injury (necrotic spotting) was recorded daily. Twenty-one days after emergence, one terminal leaflet, unshaded and fully exposed to the light, was selected and removed from the upper part of each plant. These leaflets were cleared of pigments in boiling $70 \%$ $(\mathrm{v} / \mathrm{v})$ ethanol for $2 \mathrm{~min}$, placed in room-temperature ethanol overnight, and then stained with a solution of iodine potassium-iodide (Cushman et al., 1995). Relative leaflet area exhibiting necrosis was recorded after clearing of pigments, and relative leaflet area exhibiting starch loss was recorded after staining for starch content. In each case, relative leaflet area was visually estimated to the nearest $10 \%$. Leaf area and dry mass were determined from the remaining shoot mass. Percent data were not analyzed due to the extreme differences in injury development between treatments: the large tubers resulted in mostly $0 \%$ while the small tubers resulted in mostly $100 \%$ injured area. Leaf area and dry mass data were analyzed using the analysis of variance procedure in SAS (release 6.09; SAS Inst., Cary, N.C.).

\section{Results and Discussion}

Plants propagated from either small tuber pieces or tissue-cultured plantlets appeared to be equally sensitive to the injurious effects of constant light, for injury became evident on both sets of plants within 7 to 9 days of the start of the constant-light period (Fig. 1). Injury appeared as necrotic spotting and chlorosis on young, expanding leaves. These results are similar to those of numerous other studies conducted in our laboratory of plants propagated from tissue-cultured plantlets and grown under constant light (Cao and Tibbitts, 1991; Cushman et al., 1995; Tibbitts et al., 1990, 1992, 1994; Wheeler and Tibbitts, 1986).

However, plants propagated from small vs. large tuber pieces exhibited vast differences in sensitivity to constant light. After 21 days of growth, leaflets sampled from plants of small tuber pieces exhibited extensive necrotic spotting while plants propagated from large tuber pieces were free of necrotic spotting (Fig. 2a; Table 1). In addition, leaflets from plants of small tuber pieces lost almost all starch while plants from large tuber pieces lost little starch; only one out of six leaflets sampled from plants of large tuber pieces exhibited any discernible starch loss (Table 1; Fig. 2b).

Plants grown under alternating light/dark conditions appeared uninjured after 21 days of growth, whether grown from small or large tuber pieces, and neither necrotic spotting nor starch loss was visible in leaflets sampled from these plants (Table 1).

Shoots from small and large tuber pieces appeared to grow with equal vigor and were of equal size up to 10 days after emergence (data not shown). After this time, shoots from large tuber pieces developed more rapidly, and large tuber pieces produced plants with significantly higher dry mass and leaf area than those from small tuber pieces, regardless of photoperiod (Table 1). Leaflets on the emerging shoot expanded to a much greater area on plants of

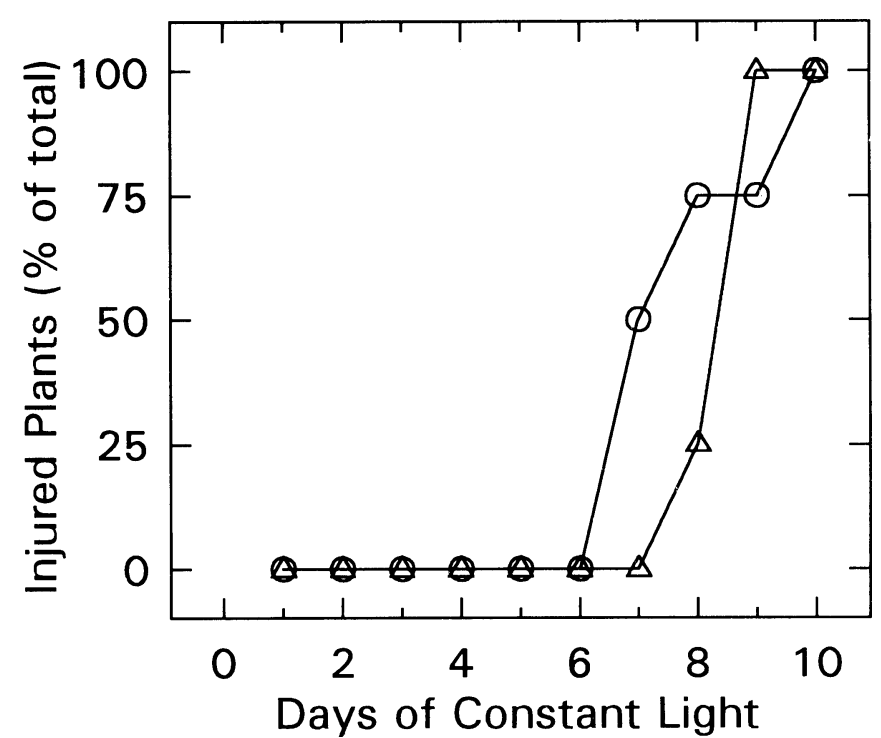

Fig. 1. Time course of constant-light injury (necrotic spotting) on the foliage of 'Kennebec' potato plants. Plants were propagated from tissue-cultured plantlets $(\Delta)$ or 1.0 -g tuber pieces $(\bigcirc)$. $n=4$.

large tuber pieces than on those of small ones. These results show that growth rate and plant vigor in the period 10 to 21 days after emergence were greatly influenced by size of the tuber-piece propagule, as was the case in other studies comparing shoot growth from small (10 g or less) vs. large (15 g or more) tubers or tuber pieces (Allen et al., 1992; Davies and Ross, 1985; O'Brien and Allen, 1992).

Although our results suggest that plants from large tuber pieces had a sufficiently rapid growth rate to avoid significant injury development, Kristoffersen (1963) reported the opposite effect of growth rate on injury development in tomato. In addition, investigations in our laboratory of potato growth under various light levels have shown that rapid and vigorous growth of young potato plants does not affect the development of constant-light injury or reduce its severity (unpublished data). Plants that were grown from tissue-cultured plantlets under PPF levels of 210,470 , or 710 $\mu \mathrm{mol} \cdot \mathrm{m}^{-2} \cdot \mathrm{s}^{-1}$ increased in shoot dry mass by $1.6,2.4$, and $2.8 \mathrm{~g}$, respectively, but developed a similar amount of injury, regardless of PPF level. Therefore, even though larger tuber pieces produced larger plants in this tuberpiece study, it appears that increased growth rate and plant vigor would not have been responsible for the lack of injury in plants propagated from large tuber pieces.

It is well known that plant responses to certain pathogens, such as viruses, are greatly affected by environment. Our results, however, indicate that constant-light injury is not caused by a pathogen because similar tuber material was used for the small and large tuber pieces and injury developed only on plants of the small pieces. Instead, our results appear to confirm the developmental or physiological nature of this injury.

Large tuber pieces have the potential of supplying more carbon assimilates to the developing shoot than small ones. However, we have reported (Cushman et al., 1995) that injury developed initially in tissue of a specific physiological stage of development, i.e., in expanding leaf tissue that had recently converted from heterotrophic to autotrophic function and, therefore, had ceased importing carbohydrates from other portions of the plant. The loss of heterotrophic function, and thus the loss of carbon importation, in expanding leaves appears to be developmentally regulated and occurs independently of the tissue's ability to support autotrophy (Turgeon, 1984). Therefore, with evidence that the specific tissue in potato leaves injured by constant light had ceased importing carbohydrates from other organs of the plant, large tuber pieces could not have prevented injury by supplying carbon assimilates to the affected tissue.

Large tuber pieces also have the potential of being a better sink for carbon assimilates than small tuber pieces. It has been shown that leaves can develop high levels of carbohydrates under conditions of low rates of translocation and low sink demand, and these high levels of carbohydrates can lead to end-product, or "feedback," inhibition of photosynthesis (Azcón-Bieto, 1983). The larger sink available to plants of large tuber pieces may act as a protective mechanism against injury. Indeed, numerous studies in our laboratory have shown that leaves of young potato plants appeared to be more affected by constant light than those of older plants. For example, leaves on plants that received constant light from the time of transplant were so severely injured that they became completely chlorotic and covered with necrotic spotting and often abscised. However, leaves on plants grown under a 12$\mathrm{h}$ light/12-h dark photoperiod for the first 10 days after transplant, and then exposed to constant light, became chlorotic and necrotic, but not to the extent of leaves on younger plants, and these leaves did not abscise. A similar response has been reported for tomato (Hillman, 1956). These observations suggest that the presence of fully developed leaf tissue on older plants was able to minimize the effects of constant light in expanding leaves in a 


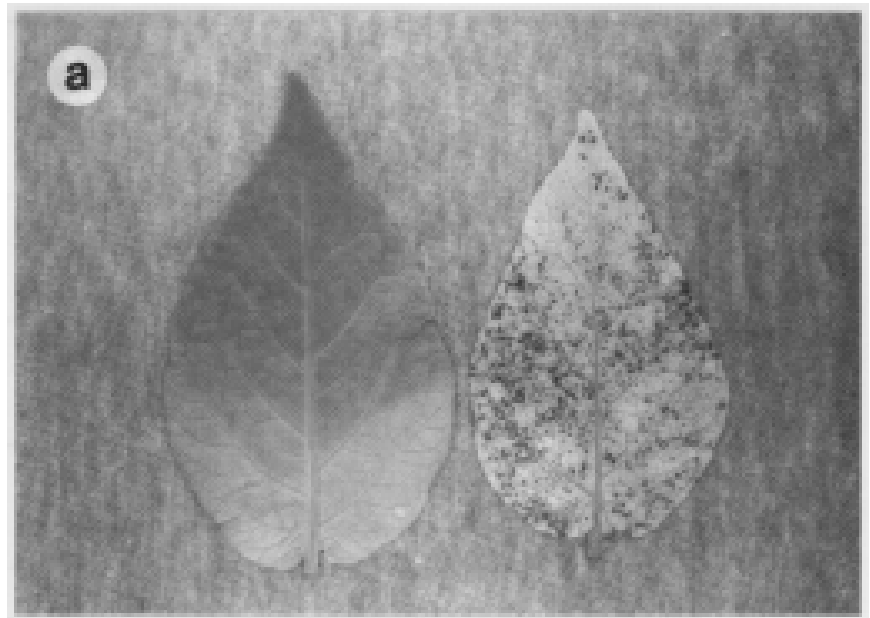

results also indicate that with the increasing use of mini-tubers ( 1 to $30 \mathrm{~g}$ ) in the extreme northern latitudes of Europe, where light periods are $20 \mathrm{~h}$ or more during the growing season, increasing incidences of this disorder may be expected.

\section{Literature Cited}

Azcón-Bieto, J. 1983. Inhibition of photosynthesis by carbohydrates in wheat leaves. Plant Physiol. 73:681-686.

Allen, E.J., P.J. O’Brien, and D. Firman. 1992. An evaluation of small seed for ware-potato production. J. Agr. Sci. (Cambridge). 118:185-193.

Arthur, J.M., J.D. Guthrie, and J.M. Newell. 1930. Some effects of artificial climates on the growth and chemical composition of plants. Amer. J. Bot. 17:416-482.

Cao, W. and T.W. Tibbitts. 1991. Physiological responses in potato plants under continuous irradiation. J. Amer. Soc. Hort. Sci. 116:525552.

Cushman, K.E., T.W. Tibbitts, T.D. Sharkey, and R.R. Wise. 1995. Constant-light injury of potato: temporal and spatial patterns of carbon dioxide assimilation, starch content, chloroplast integrity, and necrotic lesions. J. Amer. Soc. Hort. Sci. 120:1032-1040.

Davies, H.V. and H.A. Ross. 1985. Investigations on sprout growth in cv. Maris Piper: Tuber wounding effects and growth from tuber cores of different dimensions. Potato Res. 28:145152.

Hammer, P.A., T.W. Tibbitts, R.W. Langhans, and J.C. McFarlane. 1978. Base-line growth studies of 'Grand Rapids' lettuce in controlled environments. J. Amer. Soc. Hort. Sci. 103:649-655.

Highkin, H.R. and J.B. Hanson. 1954. Possible interaction between light-dark cycles and endogenous daily rhythms on the growth of tomato plants. Plant Physiol. 29:301-302.

Fig. 2. Terminal leaflets harvested from 'Kennebec' potato plants after 21 days of constant light and constant temperature. Leaflets cleared of pigments to reveal necrotic spotting (a) and then stained to observe starch content $(\mathbf{b})$. Leaflet from a plant propagated from $\mathrm{a} \approx 100 \mathrm{-g}$ (left) or a 1.0-g (right) tuber piece.

Table 1. Effect of photoperiod and potato tuber-piece size on plant growth and injury development. Shoot dry mass, leaf area, and relative leaf area exhibiting starch loss or necrosis was determined for 'Kennebec' plants 21 days after emergence.

\begin{tabular}{lcccc}
\hline \hline $\begin{array}{l}\text { Photoperiod }(\mathrm{h}) \\
\text { and tuber piece }\end{array}$ & $\begin{array}{c}\text { Shoot dry } \\
\text { mass }(\mathrm{g})^{\mathrm{y}}\end{array}$ & $\begin{array}{c}\text { Leaf area } \\
\left(\mathrm{cm}^{2}\right)^{\mathrm{y}}\end{array}$ & \multicolumn{2}{c}{ Injury (\% leaflet area $)^{\mathrm{x}}$} \\
\hline 24 & $3.1 \pm 1.2$ & $520 \pm 290$ & $98 \pm 1$ & Secrosis \\
$\quad$ Small & $9.7 \pm 0.6$ & $1690 \pm 170$ & $12 \pm 22$ & $91 \pm 18$ \\
Large & $* *$ & $* *$ & NA loss & 0 \\
& & & & $\mathrm{NA}$ \\
16 & $1.8 \pm 0.4$ & $490 \pm 120$ & 0 & 0 \\
Small & $6.9 \pm 1.3$ & $1560 \pm 300$ & 0 & 0 \\
Large & $*$ & $* *$ & $\mathrm{NA}$ & $\mathrm{NA}$ \\
& &
\end{tabular}

${ }^{2}$ Plants were propagated from small $(0.9$ to $1.1 \mathrm{~g})$ or large $(70$ to $150 \mathrm{~g})$ tuber pieces.

${ }^{y}$ Values are means of six plants or leaflets \pm SD.

${ }^{\mathrm{x}}$ Comparisons with mostly zero values were not analyzed (NA).

${ }^{*}, *$ Significance at $0.001<P \leq 0.01$ or 0.001 , respectively.

similar way that large tuber pieces were able to minimize the effects of constant light in expanding leaves of young shoots. Research directed toward understanding the allocation of carbohydrates within plants of small vs. large tuber pieces may lead to an understanding of the underlying mechanism of this disorder.
In conclusion, our results explain why constant-light injury of potato was not reported in the literature until recently, when tissuecultured plantlets began to replace the use of tuber pieces in growth chamber studies. Injury to tomato was first reported in 1929, whereas injury to potato was first reported in 1986. Our
Hillman, W.S. 1956. Injury of tomato plants by continuous light and unfavorable photoperiodic cycles. Amer. J. Bot. 43:89-96.

Kristoffersen, T. 1963. Interactions of photoperiod and temperature in growth and development of young tomato plants (Lycopersicon esculentum Mill.). Physiol. Plant. Suppl. 1:1-98.

O'Brien, P.J. and E.J. Allen. 1992. Effects of seed crop husbandry, seed source, seed tuber weight and seed rate on the growth of ware potato crops. J. Agr. Sci. (Cambridge) 119:355-366.

Tibbitts, T.W., S.M. Bennett, and W. Cao. 1990. Control of continuous irradiation injury on potatoes with daily temperature cycling. Plant Physiol. 93:409-411.

Tibbitts, T.W., W. Cao, and S.M. Bennett. 1992. Utilization of potatoes for life support in space V. Evaluation of cultivars in response to continuous light and high temperature. Amer. Potato J. 69:229-237.

Tibbitts, T.W., W. Cao, and R.M. Wheeler. 1994. Growth of potatoes for CELSS. NASA Contractor Rpt. 177646, Ames Res. Ctr., Moffett Field, Calif.

Turgeon, R. 1984. Termination of nutrient import and development of vein loading capacity in albino tobacco leaves. Plant Physiol. 76:45-48.

Wheeler, R.M. and T.W. Tibbitts. 1986. Growth and tuberization of potato (Solanum tuberosum L.) under continuous light. Plant Physiol. 80:801-804. 